DOI: $10.12957 /$ concinnitas.2019.47961

\title{
Notas sobre a interface em Harun Farocki e Robert Rauschenberg
}

\author{
Alessandra Bergamaschi ${ }^{1}$
}

\section{Resumo}

O artigo aborda a reflexão de Harun Farocki sobre as conversões - ou interfaces - entre o mundo e as imagens técnicas, tema crucial na década de 1990 devido à convergência entre novas mídias, arte e cinema. Propomos, a partir disso, uma digressão histórica sobre os sinais dessas conversões na obra de Robert Rauschenberg na passagem entre modernismo e pós-modernidade.

Palavras-chave: Filme de artista, pós-modernismo, estudos de mídia, história da arte.

\begin{abstract}
The article approaches Harun Farocki's reflection on the conversions, or interfaces concerning the image codification, which are so crucial for the new midia, art and cinema convergence in the 1990s. From this questioning we propose a historical digression about the first signs of inter mediality in the work of Robert Rauschenberg, in the transition between modernism and postmodernity.
\end{abstract}

Key-words: Artist film, postmodernism, media studies, art history.

1 Alessandra Bergamaschi é artista visual e pesquisadora ítalo-brasileira. É formada em Comunicação pela Universidade de Bolonha e inscrita no programa de Doutorado em História Social da Cultura - linha História da Arte e da Arquitetura, na PUC-Rio, com uma pesquisa sobre os efeitos da imagem técnica sobre o pictórico na obra de Jackson Pollock e Robert Rauschenberg. 
No final dos anos 1980, inaugurando uma década que será marcada por novas iniciativas de grandes instituições para integrar as imagens em movimento em suas coleções e exposições, o cinematográfico e a projeção em larga escala entram no museu. Uma das razões é de caráter eminentemente tecnológico: a maior acessibilidade de tecnologias de projeção digital, que proporcionam uma experiência equivalente à projeção cinematográfica, inaugura uma modalidade expositiva distintivamente híbrida, carregando referências à pintura mural, aos painéis publicitários, e, antes de tudo, à imaterialidade, ao ilusionismo e ao gigantismo do cinema. Ao mesmo tempo, e também pelo desenvolvimento de tecnologias digitais multiformes e mais acessíveis, o cinema é ameaçado de obsolescência. Como nota Dominique Païni, a partir dos anos 1990 torna-se patrimônio histórico, arquivo de memórias coletivas e afetivas. ${ }^{2} \mathrm{O}$ museu vem a ser um de seus refúgios e, nas práticas da arte contemporânea, abre-se espaço para o questionamento tanto de suas modalidades discursivas quanto das características materiais de seu dispositivo. Após a experiência das salas quase vazias na estreia de seu filme Videogramas da Revolução, em 1993, o próprio Harun Farocki comenta que o cinema naquele momento "estava deixando de ser um lugar de presença simbólica" ${ }^{3}$.

Uma das mostras inaugurais para esse fenômeno é Documenta 9, curada por Jan Doet em 1992, que atraiu acerca de 600.000 visitantes e teve um dos maiores orçamentos da história da instituição. Muito criticada por seu tom sensacionalista, nessa Documenta foram apresentadas instalações como The Arc of Ascent, de Bill Viola, Anthro/Socio, de Bruce Nauman, Tall Ships, de Gary Hill e Hors Champs, de Stan Douglas (todas de 1992), obras que segundo Barbara London, então curadora do departamento de vídeo do MoMA, marcaram o ingresso do vídeo em uma fase mais madura ${ }^{4}$ Outra mostra importante, que trata especificamente a então recente triangulação entre cinema, artes visuais e novas mídias é

${ }^{2}$ In Paini, Le temps exposé. Le cinéma de la salle au musée, p.26, citado em Balsom, "Architectures of Exhibition", in Exhibing Cinema in Contemporary Art, 2009.

${ }^{3}$ In Harun Farocki: quem é responsável? IMS, Rio de 16 de março a 30 de junho de 2019, Publicação da mostra, p.11.

${ }^{4}$ In Balsom, "Architectures of Exhibition", in Exhibing Cinema in Contemporary Art, 2009 . 
Passages de l'Image, curada por Raymond Bellour, Christine Van Assche e Catherine David no Centre George Pompidou, em 1990.

Os curadores realizam uma pesquisa rigorosa sobre o destino dos regimes imagéticos específicos em um momento marcado pela convergência tecnológica e pela negociação do espaço do museu, com o objetivo de trazer à tona a convergência entre cinema, fotografia, vídeo e meios digitais, deflagrada nos anos 1980, mapeando suas contaminações mútuas e as respectivas especificidades. Segundo Bellour, o advento da imagem digital não teria viciado a especificidade dos meios, mas seria uma oportunidade de reflexão, pois "as velhas imagens deveriam ser interpretadas à luz do enigma apresentado por essas imagens híbridas". A mostra apresentava um panorama de como essas 'passagens' entre meios discretos tinham interrogado o cinema durante o séc. XX, com obras de Dan Graham, Gary Hill, Thierry Kuntzel, Chris Marker, Michael Snow, Bill Viola, Jeff Wall, além de um extenso programa de filmes no cinema do museu.

É nesse contexto que, em 1995, Harun Farocki, diretor com uma vasta produção de documentários para cinema e televisão, é convidado pelo curador Régis Durand a expor e comentar a sua produção em uma mostra de artes visuais em Villeneuve d'Ascq (Lille). Além de exibir um vídeo em dois canais, Farocki instala naquela ocasião duas lousas escolares antigas, onde anota com um giz alguns comentários sobre o seu trabalho "talvez achando que a exibição de um vídeo não fosse um esforço artístico suficiente", conforme relata. ${ }^{5}$ Naquele ano será convidado a participar da mostra Face à l'histoire [Diante da História] do Centre Pompidou, onde exibe Interface, o primeiro vídeo produzido especificamente para um museu. Interface é um filme em dois canais, onde os comentários sobre o seu processo, em vez de serem anotados sobre as duas lousas, são articulados nos dois monitores que espelham recursivamente o funcionamento da tecnologia da ilha da edição.

Essa passagem oferece um ponto de partida interessante para pensarmos sobre o trabalho de Farocki segundo a proposta de Bellour na mostra Passages de L'Image, ou seja, enfatizando os momentos "entre" as imagens - as conversões, ou interfaces que marcam a codificação da imagem do analógico para as inúmeras articulações e aplicações da ótica digital - e como isso reverbera nos processos de significação e na construção das narrativas históricas. ${ }^{6}$ Farocki indaga sobre 0 funcionamento do campo visual como um terreno móvel, onde essas novas interfaces tendem a passar desapercebidas, pois são absorvidas e naturalizadas. Como nota Hal Foster em um artigo de 2004,

\footnotetext{
${ }^{5}$ Ibid. Nota 1.

${ }^{6}$ Ver também, Bellour, Entre Imagens, 1990.
} 
Como Marx, ele insinua que cada nova fase dessa história de produção e reprodução estabelece uma nova transmissão de poder e conhecimento, e, como Michel Foucault e Jonathan Crary, ele sugere que cada novo dispositivo envolva também um novo regime do sujeito. ${ }^{7}$

O impulso de desnaturalizar as codificações dos regimes imagéticos parece o motor de sua poética nos documentários realizados para cinema e televisão e, em um segundo momento, também no contexto das artes visuais. Interface, a sua primeira instalação, se distancia das duas vertentes mais exploradas do gênero "filme de artista", em ascensão nos anos 1990, a primeira magnificando o dispositivo - situações que citam o caráter imersivo do cinema ou de sua história, como as obras de Douglas Gordon - e a segunda vertente de uma arqueologia do dispositivo, na linha por exemplo de alguns trabalhos de Tacita Dean, onde projetor analógico, projeção e filme compõem o "cinematográfico", como conjunto material agora deslocado no museu - onde aparece como presença fenomenológica frágil e tremeluzente em um espaço obscurecido.

A materialidade de Interface é despretensiosa e passa longe da ordem do espetacular ou do "espectral", no sentido da imagem como fantasmagoria, dessas vertentes. A sensação é de estarmos na frente de um vídeo didático, onde o próprio Farocki, sentado em sua ilha de edição, explica a lógica aparentemente binária de seu trabalho (os dois monitores, a combinação de imagem e texto).

Este é um local de trabalho, uma mesa de edição para o processamento de imagens e sons. $O$ Painel de controle, $o$ aparelho de reprodução, o gravador. ${ }^{8}$

O trabalho do editor é construir o filme justapondo imagens, ou cenas, em uma sintaxe que se assemelha ao encadeamento da composição de um texto. O sentido é gerado através de similitudes (uma imagem é parecida com a outra) ou metáforas, onde existe um deslocamento, ou transferência, entre a primeira e a segunda imagem.

7 "Vision Quest", in ArtForum, Nov. 2004. P.158. Trad. Minha: "Like Marx, he implies that each new phase in this history of production and reproduction set up a new relay of power and knowledge, and like Michel Foucault and Jonathan Crary he suggest that each new relay involve a new regime of the subject as well."

${ }^{8}$ In Farocki, Interface, 1995, transcrição da fala. 
Essa imagem combina com essa outra? Essa imagem completa essa? Essa imagem se exclui diante da outra? Pode-se interpretar essa dualidade como uma imagem comentando a outra. Até hoje, as imagens eram comentadas com palavras ou música. Aqui imagens comentam imagens. ${ }^{9}$

O tom instrutivo nos dá a sensação de uma forma onde as imagens complementam o texto ou vice-versa, ou, como ele mesmo afirma, de um encadeamento lógico entre as imagens, mas as relações que se desdobram ao longo do vídeo desmentem qualquer relação sistematizável entre os dois níveis. Não se trata da justaposição de dois elementos no espaço nem de uma narração sintetizável, mas de uma implosão recursiva que supera até a complexidade da montagem dialética, pois o uso de dois canais possibilita desdobramentos da ordem do hipertexto, ou de várias janelas abertas simultaneamente em nossa tela - vale lembrar que, naqueles anos, a telemática começava a se difundir em larga escala.

Experimentando uma vasta gama de relações possíveis entre os dois quadros, Farocki desdobra, espelha e duplica dados sensíveis de seu processo, trazendo cenas de seus primeiros filmes, para revelar os pormenores de seu funcionamento. Em algum momento chega a encenar um incêndio na ilha de edição, enquanto os monitores mostram as imagens de Fogo inextinguivel, seu curta sobre os efeitos do napalm, de 1969. Traz também as memórias de uma mesa de trabalho anterior, onde alguns fotogramas são impressos e colados na parede introduzindo outras possibilidades de visualização:

Na parede, a cruz. Talvez um gráfico de coordenadas. Coordenadas existem pra determinar a posição. Aqui as imagens seriam as medidas determinantes. Logo a seguir, vemos o autor desocupando a mesa, até surgir uma superfície preta. Não branca como uma tela, mas preta. O roteiro salta da mesa do autor para dentro da cena do filme, um salto para o passado, para 1917, o ano da guerra, da revolução. ${ }^{10}$

Ele ilustra as passagens de seu trabalho na ilha, entre a materialidade do fazer e imaterialidade da representação. A definição de interface é justamente um dispositivo (material e lógico) graças ao qual se efetuam as codificações e decodificações entre dois sistemas: texto e imagens, imagens e realidade, entre o registro do imaginário e do simbólico.

\footnotetext{
${ }^{9}$ Ibid. Nota 6.

${ }^{10}$ In Interface, transcrição da fala.
} 
As imagens "operacionais" - imagens não capturadas por propósitos artísticos, mas para ilustrar, informar, explicar - e a sua voz em off que descreve calmamente as passagens, chocam vertiginosamente com as associações propostas. O filme emerge delas como uma formação intuitiva, que não pode ser conceitualizada a priori, como ele mesmo afirma: "foi editando esse filme que compreendi pela primeira vez como observar as imagens despretensiosamente, sequencialmente, até a construção do filme acontecer por si" 11 .

Interface nos projeta então em um espaço redundante $\mathrm{e}$ multidimensional de associações e registros heterogêneos que aponta o tempo inteiro, de forma recursiva, para a sua própria gênese. Com essa obra, Farocki apresenta com muita lucidez as estruturas generativas que irá desenvolver nos sucessivos vinte anos de produções pensadas para o espaço de museus e galerias. Ele repete duas vezes, "como é um processo demorado, podemos falar de outras coisas". ${ }^{12} \mathrm{Ou}$ seja, enquanto a máquina trabalha, ele divaga, aludindo ao percurso sem rumo típico do ensaio mas também à estranha lógica da coleção, onde a justaposição entre as várias peças acaba fazendo sentido somente a posteriori. Enquanto a máquina segue seu movimento aberrante e inarrestável, ainda há espaço, ou é necessário abrir espaço, para as fugas transversais da imaginação.

Vilém Flusser nota que a mesa de trabalho como interface entre a imagem e o mundo é uma passagem fundamental entre o gesto do produtor de imagens tradicionais (na história da arte domínio do pictórico, ou seja, de uma tela vertical), "que abstraem a profundidade da circunstância" indo do concreto ao abstrato, e o gesto do produtor de tecno-imagens, que reagrupam pontos para formarem superfícies, ou seja, indo de uma abstração ao concreto (com as devidas ressalvas). ${ }^{13} \mathrm{~A}$ máxima distância entre o produtor de imagens tradicionais e a tela é o comprimento de seu braço. Ele se encontra ao centro de suas representações e a sua mão fixa as circunstâncias em sua volta. Ao contrário, na ilha de edição, o braço opera sobre circunstâncias remotas. Em Interface, Farocki ilustra muito bem a transição entre a fita analógica, onde sente os pontos de sutura com a ponta dos dedos, e a fita vhs, onde opera indiretamente, apertando botões. Tanto nesse gesto quanto no gesto de contar dinheiro, recurso simbólico por excelência, ainda existe uma

\footnotetext{
${ }^{11}$ Harun Farocki: quem é responsável?, P.10 e Interface.

${ }^{12}$ Farocki, Interface, 1995.

${ }^{13}$ Flusser, O universo das imagens técnicas. Elógio da superficialidade, 1985, P.19.
} 
dimensão táctil, mas ela engana, pois aqui "a essência pouco coincide com a aparência" 14 .

No último estágio de abstração da imagem, com a computação digital, a conversão numérica da imagem e da visão destroem definitivamente $\mathrm{o}$ referente, e se tornam interfaces não mais entre $\mathrm{o}$ mundo e as imagens mas entre conjuntos de dados e simulações do mundo. Recorrendo a tais imagens, a distinção entre as dimensões da imagens não faz mais sentido (duas, três), pois adentramos um universo imaginário transformado, onde, retornando a Flusser, "o poder da imaginação faz com que a rigidez da circunstância, anterior à produção de imagens, seja substituída por fluidez e maleabilidade" 15 . Aqui, as circunstâncias representacionais se alienam não somente do alcance do braço, mas também do controle operacional de um sujeito remoto, pois cortando a relação com a concretude do mundo introduzem a possibilidade da realidade ampliada, por exemplo, dos games.

Farocki elabora esse tema em um longa para o cinema de 1988, um pouco anterior a Interface, Imagens do mundo e inscrição de guerra, onde elabora, a partir de inúmeros registros, uma reflexão sobre a gênese desse processo de abstração. O ponto de partida, paradoxalmente, é a centralidade da visão e da racionalidade do homem no Renascimento, quando a geometria projetiva, bem ilustrada nos desenhos de Leonardo da Vinci e Albrecht Dürer, permite projetar o mundo inteiro no plano focal humano, antecipando o fotográfico. A narração não linear de Farocki atravessa então o Iluminismo como ápice desse processo de "esclarecimento" através da razão, que será ameaçado pelo progresso técnico decorrente desses princípios, até causar a própria alienação do humano.

Nessas reproduções não mediadas por nosso olhar, onde "são produzidas mais imagens do mundo do que os soldados podem analizar" aparece, inexorável, o automatismo da máquina. ${ }^{16}$ As medidas do corpo e da natureza, convertidas em desenhos por Leonardo, Durer ou de Piero della Francesca, são substituídas por sistemas que codificam regras e dados em imagens ou que reconhecem, armazenam e cruzam dados a partir de imagens, em uma progressiva automatização do ver e do imaginar que nos exclui tanto da visão quanto da análise. A guerra utiliza e potencializa as tecnologias da visão, argumenta Farocki no filme, por suas necessidades de classificação e medição, mas a maneira como essas imagens são interpretadas depende das regras de funcionamento da

${ }^{15}$ Flusser, O Universo das Imagens Técnicas. Elógio da Superficialidade, p.21.

${ }^{16}$ Farocki, Imagens do mundo e inscrição de guerra, 1988. 
máquina, com seus movimentos inexoráveis. Retorna então o questionamento conclusivo de Interface:

Esta mesa de edição seria talvez um codificador, ou um decodificador? Trata-se de codificar um segredo ou de mantê-lo? Eis o enigma da interface, que mostra escondendo. ${ }^{17}$

As imagens aéreas ainda analógicas onde os aliados retratam o campo de extermínio de Auschwitz sem o reconhecer por estarem com outros objetivos, são um exemplo da ausência dessa mediação do olhar humano como um recalque trágico, onde o homem acaba se ausentando de sua própria história, que seguirá o seu curso em um universo operacional já dado e determinado pelos automatismos das máquinas de guerra (fig.2) ${ }^{18}$. A interface entre mundo e imagens torna-se uma barreira que nos exclui dessa duplicação do mundo, onde a mediação técnica não funciona mais como prótese da percepção, mas substitui a nossa função analítica, traindo definitivamente o enaltecimento e a centralidade da razão humana e colocando em seu lugar a razão dos poderes hegemônicos. A distração, que no início do século XX parecia um vício a ser combatido para continuarmos produtivos, torna-se condição existencial.

Flusser continua a sua análise sobre a produção dessas tecnoimagens alegando que mesmo que as circunstâncias passem a não estar mais "diante da mão", elas ainda "parecem estar lá". Ou seja, quando a interface funciona, ainda temos a sensação de estarmos no controle da realidade oferecida pelas imagens técnicas. Em razão disso, a partir da década de 1980 conceitos como diferença, repetição, o traço, o simulacro, a hiper-realidade e a fragmentação da imagem se tornarão centrais para a reflexão estética e filosófica. Com o alastramento dos novos meios digitais, nessa década a cultura visual passa a absorver, produzir, recodificar e por último naturalizar aparências "sintéticas" com uma velocidade e alcance inéditos, passando a ser necessário, como diz Farocki, "ter tanto cuidado com as imagens quanto com as palavras, já que imagens e palavras estão entrelaçadas em discursos, redes de significados." ${ }^{19} \mathrm{Ou}$ seja, nesse momento as evidências de que é impossível escapar do teor simbólico da imagem, que perdeu qualquer transparência, ou 'realismo', tornam-se irrefutáveis.

\footnotetext{
17

${ }^{18}$ Harun Farocki, Imagens do mundo e inscrição de guerra, 1988, filme analógico 16 $\mathrm{mm}$, cor e pb, 75'. Frame do filme.

${ }^{19}$ Idem.
} 
A partir desse questionamento e seguindo o método de Farocki, propomos a seguir uma digressão, buscando na delicada e não tão clara transição entre o modernismo e o pós-moderno na história da arte, alguns sinais dessa transformação que sirvam de referência para esboçarmos uma genealogia transversal do conceito de "interface" - entre meios e dimensões da imagem - partindo agora da linguagem pictórica. A figura de Robert Rauschenberg é interessante nesse sentido, pois se aproxima muito do produtor de imagens que se depara com gestos manuais jamais executados antes, que não trabalha a matéria mas se dirige "contra superfícies, a fim de informá-las". ${ }^{20}$ As suas telas - chamadas pelo crítico Leo Steinberg de flatbed, ou seja, superfícies horizontais, ou de trabalho, são cruciais, na história da arte norte-americana, pois inauguram a passagem do abstracionismo à arte pop no final dos anos 1950, em um contexto onde os primeiros sinais da revolução da eletrônica começavam a reverberar na arte.

Essa orientação horizontal, que John Cage define como "visão aérea", é um plano pictórico que se tornará característico da produção artística dos anos 1960, enquanto "superfície cujo ângulo em relação à postura humana é a precondição de seu conteúdo transformado". ${ }^{21}$ Rauschenberg adota repetidamente abordagens que retomam essa orientação horizontal, enfatizando a materialidade e a solidez necessárias para que os rastros da ação, ou seu apagamento, se imprimam no quadro nos combines, em Automobile Tire Print, desenho de 1953 em colaboração com o próprio John Cage, ou ainda em Erased De Kooning, do mesmo ano, onde a fantasmagoria do desenho apagado do artista flutua no papel desgastado pela borracha, uma ação que só é possível graças ao plano sólido que estava por baixo.

Como nota Steinberg, através da inscrição do ato de friç̧ão da borracha na mesa, Rauschenberg não estaria mudando - como Pollock somente o plano em que o trabalho é realizado, mas o ângulo em que a nossa imaginação confronta a obra. Rauschenberg reconfigura a evocação de um espaço de mundo que reproduz a natureza para um homem ereto, axioma compartilhado na pintura desde o Renascimento até o expressionismo abstrato, em um campo horizontal opaco, como os que fornecem a base para processos operacionais do cálculo e da escrita. Introduz tanto simbolicamente quanto materialmente superfícies duras, com limites definidos, em uma escala que pode ser controlada pela

\footnotetext{
${ }^{20}$ Steinberg, Outros Critérios, p.16, 1972. O texto é baseado numa palestra proferida no MoMa em 1968. "The message changes in the combine-drawings, made with pencil, water color, and photographic transfer: (a) the work is done on a table, not on a wall." In Cage, Silence and Other Writings, p.105.

${ }^{21}$ Idem.
} 
gestualidade humana:

tampos de mesa, chão de ateliê, diagramas, quadros de aviso qualquer superficie receptora onde sejam espalhados objetos, se insiram dados, onde informações possam ser recebidas ou impressas de maneira coerente ou confusa. ${ }^{22}$

A referência de Steinberg à influência da revolução da eletrônica, em curso nos Estados Unidos naqueles anos, que influencia indiretamente reorganização perceptiva do pictórico operada por Rauschenberg, é bastante direta quando fala de "informações" e "dados". Esse tema adquire centralidade e será tratado extensivamente por Marshall McLuhan, notório comentarista da influência dos meios de comunicação sobre o sensório humano, que escreve A Esposa Mecânica em 1951, um primeiro ensaio onde antecipa alguns conceitos do mais complexo Understanding Media, de 1960. Nessa segunda obra, McLuhan relata a iminência da mudança epocal em curso - após os cerca de 300 anos de sujeição ao movimento centrífugo gerado pela fragmentação dos meios mecânicos, o mundo começaria a sofrer, naqueles anos, os efeitos da implosão dos meios eletrônicos, que se por um lado implicam a presença remota de sujeitos 'operacionais' e técnicas de geração de imagens sem a mediação direta do olhar, por outro diminuem as distâncias geográficas e entre os corpos. ${ }^{23} \mathrm{~A}$ abstração da imagem numérica engendra uma relação com as intensidades do corpo, por exemplo a partir do reconhecimento do calor, com efeitos sensíveis sobre as possibilidades de controle e colonização de nossas reações. McLuhan preconiza também a tendência à simulação tecnológica da consciência e aos processos de conhecimento, que hoje se concretizam, por exemplo, na realidade ampliada dos games e em outros fenômenos.

Esse ponto de vista não proclama a história de uma pureza originária da percepção humana, assim como é evidente que a linguagem pictórica já havia absorvido e elaborado as transformações introduzidas pela câmera escura através do desenvolvimento da ótica e do fotográfico. Ao converter o plano pictórico em uma superfície relacionada ao fazer, porém, Rauschenberg interrompe a codificação histórica do visível sedimentada na linguagem pictórica. Essa ruptura, ou deslocamento na materialidade do fazer pictórico, the permite implementar outras perspectivas sem utilizar o artifício da metáfora ou a literalidade absoluta do conceitualismo, mas através da liberdade de associar a mancha ao

${ }^{22}$ Ibid. Nota 17, p.117.

${ }^{23}$ Tadeu Capistrano, notas da palestra sobre o filme Imagens do mundo e inscrição de guerra, IMS, 11/05/19. 
signo e a marcações que não passam pela discriminação do olhar humano - que, como vimos, ganharão muita relevância com os desenvolvimentos da ótica nas tecnologias de guerra.

A mesa permite a permuta entre esses códigos visuais heterogêneos, fazendo de suas obras interfaces entre a pintura e a fotografia, e, como vamos tentar explorar adiante, entre a pintura e a escultura (os combines). Assim como vimos acontecer nos filmes de Farocki, a obra de Rauschenberg reflete as possíveis convergências e conversões entre diversos meios e linguagens. Suas telas sinalizam a passagem do pictórico modernista, ainda fortemente marcado pela teoria de Clement Greenberg sobre a especificidade dos meios, para um contexto onde o campo da obra se abre para as refrações da imagem técnica - o índice fotográfico - e para o registro simbólico linguagem.

Multiplicando os pontos de vista e introduzindo veladuras e opacidades, Rauschenberg afirma a impureza necessariamente intrínseca tanto ao realismo do fotográfico quanto à abstração pictórica. São os primeiros reflexos de uma condição histórica onde, como nota Jameson, tudo adquire visibilidade e a atenção estética tende a dissipar-se, substituída por uma visão sem foco, ou multifocal, atraída pelos infinitos espelhamentos e rebatimentos de realidades 'impuras'. ${ }^{24}$

No contexto dessa história, que podemos assimilar a uma história das refrações do realismo no campo da arte, as decisões tomadas por Rauschenberg se convertem em um movimento que tenciona a centralização do mundo a partir do homem operada no Renascimento. Rauschenberg, como Duchamp, não se refere mais à tentativa de representar as aparências do mundo no campo autônomo da pintura, mas opera através do reconhecimento da transformação da própria concepção do referente, ou realidade. Segundo Leo Steinberg, o artista teria sinalizado essa mudança radical deslocando o tema da arte do sujeito natureza para o sujeito cultura e, assim, determinando o ingresso do campo da pintura para práticas definidas pós modernas. ${ }^{25}$

A matéria de Rauschenberg é o heterogêneo, mas a sua sedimentação nas camadas que se entrelaçam nivelando na superfície

\footnotetext{
${ }^{24}$ Jameson, A virada cultural, 1998, p.110.

${ }^{25}$ Uma transição de tamanha magnitude não se daria no arco de uma geração, ou por obra de um único artista, mas através de sinais e intuições sedimentados, que se tornam reconhecíveis somente após certo distanciamento histórico. As Ninfeias de Monet, ou a transmutação, atuada por Mondrian, do céu e do mar em sinais positivos e negativos, seriam reorientações da mesma natureza, mas o Grande vidro de Duchamp, o Urinol inclinado para cima, assim como os Rotorelevos, talvez representem os aportes mais conscientes a essa transformação, que implica um afastamento do olhar humano associado à representação do natural e à codificação de seus gêneros (paisagem, natureza morta, retrato).
} 
detalhes anacrônicos, traz um dado entrópico que, a partir da ação de selecionar, isolar do mundo empírico, combinar, digerir e apagar, devolve ao mundo imagens que ainda apresentam uma composição formal. Isso configura outra maneira de desvirtuar o que emoldura a percepção, nesse caso os fundamentos do realismo tanto pictórico quanto fotográfico, e afirma a materialidade da tela e do papel como superfícies planas e rígidas - verdadeiros anteparos ou interfaces que bloqueiam e revelam imagens 'operacionais', como as manchas residuais de alguma ação, fragmentos de fotografias, mensagens e inscrições gráficas. Quando escreve sobre as telas de Rauschenberg, John Cage alega não se tratar de composições, mas de visões distanciadas

"como mapas, cujos elementos podem ser removidos $e$ substituidos por outros através de circunstâncias análogas ao nascimento e à morte, a uma viagem, uma arrumação ou ao desordenar as coisas na casa. "26

Ou seja, a tela retém pequenos eventos, ou em alguns casos, especialmente na série Dante's Drawings reporta fatos reciclados da memória coletiva americana e rearranjados nesse plano etéreo, que dissolve as relações lineares e causais da narração. Uma sutura de elementos que nos devolve uma totalidade onde emergem associações intermitentes e falhas.

Aparecem então os primeiros sinais de um sujeito descentralizado não somente pela linguagem, mas que tampouco continua ao centro de suas representações. Ou seja, entre o sujeito e o mundo se interpõe a soma dos discursos que compõem a construção cultural da visualidade, como uma interface que o protege do caos e ao mesmo tempo limita o que ele pode ver. Esse dado, que ofusca definitivamente a transparência da visão, será teorizado pontualmente por Jaques Lacan em 1964, no Seminário XI, onde introduz da noção de Olhar e de anteparo

A implicação de seu percurso teórico é que, ao fixar o olhar sobre algum objeto, o sujeito ocupa uma posição dupla. Existe um cone, simétrico e oposto ao primeiro - nosso ponto de vista - que emana do objeto que estou olhando:

Não sou simplesmente esse sujeito puntiforme localizado no ponto geométrico a partir do ponto em que a perspectiva é

\footnotetext{
${ }^{26}$ In Silence and other writings, Trad. Minha: "This is not a composition. It is a place where things are, as on a table or on a town seen from the air: anyone of them could be removed and another come into its place through circumstances analogous to birth and death, travel, housecleaning, or cluttering". P.99.
} 
compreendida. Não há dúvidas de que no fundo de meus olhos, a figura está pintada. A figura está certamente dentro dos meus olhos. Mas eu, eu estou na figura. ${ }^{27}$

O sujeito de Lacan é o sujeito convocado pelo Olhar do objeto ou da cena que está olhando. A intersecção entre os dois cones, a imagem que se forma no meio, é conceitualizada através da noção de anteparo, ponto de mediação que conforma ou delimita o Olhar em uma imagem. Em certo sentido, o 'domestica', pois 'ver sem anteparo seria deixar-se tocar pelo Olhar ou cegar pelo Real'. ${ }^{28}$

A constituição do anteparo depende do fato de que a visão é socializada: como expõe Norman Bryson, entre o sujeito e o mundo se insere 'a soma de discursos que compõem a visualidade como construção cultural'. ${ }^{29} \mathrm{Hal}$ Foster entende o anteparo lacaniano de forma análoga, como a 'reserva cultural da qual cada imagem é uma instância', ou os 'códigos da cultura visual'. ${ }^{30}$ A dimensão socializada da visão nos captura em uma rede semântica que vem de fora e que vem sendo modificada pelas relações com as tecnologias de codificação e reprodução da imagem. Essa dinâmica complexa, que determina a nossa percepção do mundo, se configura como histórica, relacional (redefinida pelas interações com os objetos, o ambiente e a tecnologia) e, por isso, em evolução contínua.

Entre a retina e o mundo se insere uma interface de signos, históricos e culturais, que demarca a constituição de um significante no campo visual. Na terminologia de Lacan, algo da ordem do simbólico, que pode ser interpretado através da linguagem -por exemplo, o fato de que esses objetos têm um nome. ${ }^{31}$ Lacan usa o notório exemplo da lata de sardinhas que brilha no mar - e que podemos associar imediatamente ao lixo que se tornou ou ao alumínio que reflete tão bem a luz do sol. Ou seja, não estou olhando para algo que chama a minha atenção somente por refletir a luz, um fenômeno ótico, mas pra um objeto inteligível, que faz parte de uma experiência já parcialmente codificada no meu imaginário.

Conforme afirma Lacan, a pintura sempre funcionou como

${ }^{27}$ Le Seminaire de Jacques Lacan, Livre XI [Paris: Editions du Seuil, 1973], p. 89. Citado in Foster, O retorno do Real, p.x.

${ }^{28}$ Foster, Ibid., p.x.

${ }^{29}$ Brison, The Gaze in the Expanded Field", in Foster (Org.), Vision and Visuality, pp.87114.

${ }^{30}$ Foster, Ibid., p.x.

${ }^{31} \mathrm{O}$ acesso ao simbólico nos permite, em certa medida, jogar com essa máscara, que isola alguns elementos excluindo o resto. É oportuno ressaltar, porém, que se trata de um domínio parcial, que depende do espaço oscilante onde estamos imersos, do mundo como 'cena onde temos que nos inserir', ou seja, onde somos implicados, como objetos da percepção do outro, figuras anônimas ou celebridades . "The Gaze in the Expanded Field", in Foster (Org.), Vision and Visuality, pp.87-114. 
anteparo, ou seja, os artistas sempre brincaram com essa máscara, que traz uma organização do Olhar por trás das formas, ou que "nos empresta uma certa modalidade do Olhar". 32

Vocês veem, podemos dizer que sempre está cheio de olhares lá detrás. Nada de novo é introduzido a esse respeito pela época que André Malraux distingue como moderna, essa em que vem a dominar o que ele chama o monstro incomparável, isto é, o olhar do pintor, que pretende impor-se como sendo, apenas ele, o Olhar. ${ }^{33}$

Enquanto na arte clássica o ordenamento do Olhar se dava através de ícones e no modernismo o Olhar não prescinde do gesto, em Rauschenberg a presença da mesa de trabalho bloqueia parcialmente o olhar do pintor e permite mediar a entrada em campo das intensidades do corpo - a pressão da mão que transfere o desenho - e de uma pluralidade de imagens encontradas que carregam seu universo de retóricas e conotações. Signos históricos e culturais em circulação, fragmentos fotográficos e diagramas selecionados por um olhar distraído e contaminados por outras marcas indiciais. ${ }^{34}$

Com a difusão dos meios de comunicação de massa em ato nos anos 1950, se por um lado a imagem volta a ter uma centralidade e nos tornamos mais conscientes da existência de um campo do visível cada vez mais codificado e manipulável, por outro pode surgir a aspiração de uma experiência originária e não mediada, 'fora' da bolha midiática. No contexto aqui referido, isso se reflete na aspiração à autonomia da pintura abstrata, que idealmente resistiria aos ataques do mundo empírico, oferecendo um laboratório incontaminado da visualidade. $\mathrm{O}$ modernismo artístico poderia, assim, ser associado à 'liberdade' da imaginação, sem insinuar a sua inscrição na retórica mais ampla da modernidade.

Ao agrupar no mesmo plano pictórico signos de diferentes

\footnotetext{
32 Segundo Callois, os animais que se mimetizam não o fazem por alguma finalidade, mas por puro luxo ou por serem capturados no espaço circunstante. A máscara ou a mancha, que nos animais se configuram como reações quase involuntárias ao meio, aparecem de forma mediada no ser humano. "O sujeito - o sujeito humano, o sujeito do desejo que é a essência do homem — não é de modo algum, ao contrário do animal, inteiramente preso por essa captura imaginária. Ele se demarca nela. Como? Na medida em que ele isola a função do anteparo e joga com ela. O homem, com efeito, sabe jogar com a máscara como sendo esse além daquilo que há o olhar. $\mathrm{O}$ anteparo é aqui o lugar da mediação." Lacan, "O que é um quadro", in O Seminário. Livro 11. Os quatro conceitos fundamentais da psicanálise, 1964, p.105.

${ }^{33}$ Lacan, "O que é um quadro", p.110.

${ }^{34}$ A distinção do Olhar é de Lacan, in xxx
} 
naturezas, sempre residuais e fragmentados, Rauschenberg ao contrário concorre a desfazer esse mito: através dos "discursos múltiplos sobre a visão embutidos na arena social", incorpora uma nova sensibilidade, onde o observador de suas telas se transforma em espectador. ${ }^{35}$ Pulverizando os pontos de vista, convoca um olhar nunca estável, mobilizado por algum detalhe ou codificando alguma inscrição - um olhar não mais ao centro da representação enquanto receptor daquela mensagem. Desloca assim a visão para o campo da visualidade, marcando a irrupção, na pintura, do significante (as palavras) e de um sujeito "sem lugar, entre as palavras e as imagens". ${ }^{36}$

No entanto, recorrendo a técnicas pictóricas como o pentimento, ou às poças aquareladas e às finas camadas de guache que velam os detalhes fotográficos, como vimos oculta as possibilidades de leitura: como Farocki e sua montagem implosiva, alude a um regime de legibilidade, mas desmente o tempo todo uma interpretação estável.

Ao agrupar no mesmo plano pictórico signos de diferentes naturezas e retóricas, Rauschenberg cria uma interface onde existe uma equivalência entre ícones, índices e símbolos - onde o "visível" é assim no "comunicável", revelando as veladuras da suposta transparência do mundo. Isso ocorre da mesma maneira com o colecionador, que pode gerar correspondências da ordem do sonho entre seus objetos, justamente porque eles já são capturados em uma rede semântica que antecede essa seleção, tornando-a 'fora do comum'.

É importante ressaltar que esse processo de revelação do simbólico não é assimilável a uma leitura iconográfica, como por exemplo a de Panofsky, que traduz imagens necessariamente icônicas em termos linguísticos (o oposto seria uma imagem idealmente 'abstrata'). Ao aglutinar várias categorias de signos no mesmo plano pictórico, como vimos, Rauschenberg aponta para um realismo e uma abstração relativos, que coabitam qualquer imagem e a própria visão, e que terá reflexos importantes sobre as refrações do realismo mais tarde elaboradas na arte pop.

Essa cegueira parcial é central no método de Rauschenberg, como se ele procurasse sistemas de encobrimento que confundem os códigos de leitura tanto do pictórico quanto da imagem técnica, apontando, como Farocki mas a partir de uma discussão sobre o pictórico, para a necessidade de questionar a transparência das imagens. Como as associações e os registros heterogêneos de Interface, são fragmentos de

\footnotetext{
${ }^{35}$ Ibid. nota 11.

${ }^{36}$ Diferença apontada por Bryson em "The Gaze in the Expanded Field", in Vision and Visuality. A segunda citação é de Rivera, in $O$ avesso do imaginário, p.11.
} 
palavras, objetos, tecidos ou fotografias aglomerados por debaixo de superfícies translúcidas, ou definitivamente opacas, entre signos de diferentes naturezas. Imagens fotográficas recortadas ou transferidas de seus contextos, que afirmam a sua presença justamente por serem deslocadas e reconfiguradas em arranjos análogos à coleção de Benjamin:

... uma organização surpreendente, incompreensivel para uma mente profana. (...) Uma espécie de desordem produtiva é o cânone da memória involuntária assim como do colecionador. ${ }^{37}$

Em Bentam, de 1955, por exemplo imagens, peles, jornais, tecidos e objetos encontrados nas proximidades do ateliê são selecionados (estratégia análoga ao ready-made e típica do fotográfico) e assemblados na superfície da tela em uma película onde, ao contrário da colagem, a tensão entre os materiais e os objetos é anulada em sua equiparação ao estatuto de imagem. Rauschenberg costumava repetir que "nunca deixara se sentir um fotógrafo, embora usasse outros meios", havendo esse sentido sofisticado de fotografia o que ele incorpora em sua obra, que aponta mais para o que a imagem esconde do que para o que ela revela. ${ }^{38}$

Encontramos alguns indícios da sua maneira de pensar a imagem em duas séries iniciais, Scatole (caixas) e Feticci Personali (fetiches pessoais), que ele produz entre 1952 e meados de 1953 em uma viagem com Cy Twombly a Roma e ao norte da África (Casablanca e Marrocos), sendo exibidas durante a sua estadia na Galleria L'Obelisco em Roma e, logo em seguida, na Galleria d'Arte Contemporanea Lungarno delle Grazie, em Florença. Essa viagem representa um hiato interessante na trajetória de Rauschenberg, logo após a produção da série das White Paintings e das Black Paintings (1951) e antes dos primeiros Combines, que realiza em sua volta aos Estados Unidos, em 1954.

Scatole é um conjunto de caixas de vários tamanhos $\mathrm{e}$ proveniências contendo fotografias e materiais como areia, ossos, fios de cabelo, penas, pedras, conchas, missangas, insetos e outras 'memorabilias' de viagem. Essas composições, que podem lembrar por sua matriz surrealista a série de Shadow Boxes de Joseph Cornell, trazem também o dado concreto dos materiais, característica que será associada pelo diretor

\footnotetext{
${ }^{37}$ Benjamin, "O colecionador", in Passagens.

${ }^{38}$ Rauchenberg tinha uma formação formal em fotografia. "Estudara fotografia na Black Mountain com Hazel-Frieda Larsen, com os fotógrafos conhecidos Harry Callhan e Aaron Siskind e tinha acompanhado os seminários de Beaumont Newhall: o primeiro curador do departamento de fotografia do Museu de Arte Moderna de Nova York." In Caruso, "Robert Rauschenberg alla Galleria L'Obelisco. Scatole e feticci personali", in Caratozzolo, Schiaffini e Zambianchi (Org.), Irene Brin, Gaspero del Corso e la Galleria L'Obelisco, p.212.
} 
da galeria L'Obelisco à influência da pesquisa informal de Alberto Burri, que no ano anterior havia exposto a série Neri (tela coberta de alcatrão) e Muffe (mofo obtido com tinta a óleo e pedra-pomes) na mesma galeria, e entrara em contato com os dois americanos. O segundo grupo de trabalhos consiste em um conjunto de mobiles feitos de plumas, crinas de cavalos, pedrinhas e espelhos, fetiches ou objetos rituais - móveis porque, ao contrário das lembranças guardadas nas caixinhas como pequenos segredos, são pendurados nas áreas externas da galeria, nas árvores do jardim e no busto do poeta Horácio, ironia que foi pouco apreciada pelos críticos italianos. Em um texto que o próprio Rauschenberg produz para a mostra, os materiais são descritos:

Os materiais utilizados para essas construções foram escolhidos por das duas razões: pela a riqueza de seu passado - como os ossos, cabelos, panos desbotados e fotos de luminárias quebradas, penas, paus, pedras, cordas e cordas; ou por sua vívida realidade abstrata - como os espelhos, os sinos, as partes de relógios, os insetos, as franjas, as pérolas, os vidros e as conchas. ${ }^{39}$

Assim, os materiais das 'construções' - note-se que ele evita usar um termo mais específico - são escolhidos pela 'riqueza de seu passado' ou por sua 'vívida realidade abstrata', ou seja, por características opostas. Ao mesmo tempo não parece haver muita diferença entre as variedades de elementos dos dois grupos. As caixas são compostas por conjuntos heterogêneos, índices de pequenos fazeres, de esquecimentos, coordenadas de passagens ou de momentos específicos, todos eles nivelados na superfície da imagem, já que, como descreve o próprio Rauschenberg, "o interior de uma caixa pode parecer uma natureza-morta fotográfica antes da ser fotografada" ${ }^{40}$. Além da referência originariamente pictórica da natureza-morta, o artista aponta aqui para a possível permutação entre a tridimensionalidade do objeto e a bidimensionalidade da fotografia, como quando Farocki ilustra as passagens entre a materialidade do fazer a imaterialidade da representação. Rauschenberg revela aqui um pensamento já em linha com os Combines que realizará logo em seguida, de volta para os Estados Unidos - construções, ou interfaces, entre a pintura e a escultura, ou seja, 'imagens', no sentido literal do termo.

${ }^{39}$ Trad.minha. The Material used for these Constructions were chosen for either of two reasons: the richness of their past: like bone, hair, faded cloth and photos broken fixtures, feathers, sticks, rocks, string, and rope; or for their vivid abstract reality: like mirror, bells, watch-parts, bugs, fringe, pearls, glass, and shells." Ibid. p.211.

${ }^{40} \mathrm{Trad}$. Minha "the full inside view of a box may look like a photographic still-life before the picture has been taken". Idem. 
[do lat. imago-gĭnis]. - 1.a. Forma externa de objetos, como percebidos pelo sentido da visão; representação com meios técnicos ou artísticos da forma externa de uma coisa real ou fictícia. $^{41}$

Minutiae, por exemplo, um dos primeiros Combines, de 1954 (óleo, papel, tecido, jornal, madeira, metal e plástico com espelho em uma estrutura de arame), forma literalmente um anteparo, um biombo (furado) que oferece uma superfície de apoio para um patchwork de retalhos, pinceladas, fotografias (fig.3). ${ }^{42} \mathrm{~A}$ tela se desdobra no espaço, mas essa tridimensionalidade parece mais funcional a uma articulação planar do que a formação de um objeto escultórico. Untitled, do mesmo ano, funciona estruturalmente como um armário, algo que desdobra 'dentros' e 'foras' onde os planos de apoio para imagens, como 'formas externas de algo real ou fictício', complexificam a condição da tela mas não chegam a se fechar em um objeto.

Ao mesmo tempo, com as caixas, Rauschenberg recupera limites físicos bem definidos para a obra, reafirmando certa tensão com o extracampo que tinha se dissolvido nas White Paintings. Elas funcionam como pequenas caixas cênicas onde são condensadas lembranças de viagem, sugerindo, como é típico do gênero souvenir, não um itinerário específico, mas a prova do isso foi turístico, que se converte em um estive lá. Ao contrário das caixas de Cornell, que se configuram como mostruários ou pequenas vitrines, todas elas têm uma tampa que alude à ordem do segredo, do que não seria dado a ver. Ou seja, a dimensão da caixa, a mesma do biombo ou do armário, introduz a possibilidade de uma superfície que se interpõe entre o olhar e o mundo, uma interface que codifica e ao mesmo tempo bloqueia parcialmente ou integralmente a visão. Rauschenberg parece assim antecipar a impossibilidade de escapar do teor simbólico da imagem, que perderá qualquer transparência, ou 'realismo' até chegar, nos anos 1990, quando vimos que simulacros e imagens não mediadas pelo olhar se tornarão centrais para a reflexão estética e filosófica.

Outras imagens interessantes nesse sentido são algumas fotografias em médio formato que oferecem indícios ulteriores sobre a sua poética.

\footnotetext{
${ }^{41}$ trad. minha: immàgine (letter. imàgine) s. f. [dal lat. imago -ğnis]. - 1. a. Forma esteriore degli oggetti corporei, in quanto viene percepita attraverso il senso della vista rappresentazione con mezzi tecnici o artistici della forma esteriore di cosa reale o fittizia. Verbete da Enciclopedia Treccani Online, http://www.treccani.it/enciclopedia/tag/immagine/

${ }^{42}$ Robert Rauschenberg, Minutiae, 1954, combine: óleo, papel, tecido, jornal, madeira, metal e plástico com espelho em estrutura de madeira, $214.6 \times 205.7 \times 77.5 \mathrm{~cm}$.
} 
Tomamos por exemplo a sequência de fotografias de Cy Twombly que sobe a escadaria do Aracoeli, enquadrado da cabeça pra baixo, Roman Steps (I, II, III, IV, V), ou, na mesma folha de contato, Cy + Relics, onde o artista é retratado no Palácio dos Conservadores ao lado de fragmentos de esculturas em mármore, como uma mão gigante com o indicador apontado pra cima, que se repete em vários quadros, ambos mostrados na figura $4 .{ }^{43}$

No caso de Roman Steps, as imagens parecem uma sequência de fotogramas de um filme - talvez alguma referência à cena do encouraçado Potemkin, mas aqui temos uma única figura humana imóvel entre as linhas horizontais e gráficas da escadaria. Esse corpo é estático e mutilado como uma estátua (sem cabeça) sugere, no entanto, quando os frames são expostos em sequência, sugere um movimento em direção à câmera. $\mathrm{Ou}$ seja, existe uma tensão entre a imobilidade da história e o grafismo da animação que quebra o dado documental da fotografia. As imagens de $\mathrm{Cy}$ entre as relíquias são por outro lado interessantes porque a sua presença diminuta abre uma fenda temporal, na duração abstrata dessa pre-história da arte. $\mathrm{O}$ corpo do artista se ajusta no espaço estreito entre a coleção inamovível daquelas ruínas, dando-nos ao mesmo tempo uma ideia precisa de sua escala monumental. A foto do busto de Cy pensativo, visto de cima com uma rotação estranha, onde parece olhar para o resto das fotos da mesma folha de contato, introduz um registro afetivo da memória de viagem que traz uma temporalidade subjetiva, reconfigurando o corpo abstrato do outro frame como uma ocorrência específica, contextualizada. Ou seja, essas imagens o tempo inteiro são e não são (documentação, lembrança), ou, apontando de novo para uma dimensão intersticial, existem entre vários registros que funcionam de contraponto um ao outro, revelando a insubstancialidade da imagem.

Porém, para concluir, é importante notar que Rauschenberg ainda 'compoé' - essas composições decentralizadas incentivam um olhar móvel e investigativo, que mapeia a tela buscando relações, oferecendo enigmas em vez de estabilizar o olhar em um quadro harmonioso. Eles não negam a composição, como o all-over do abstracionismo, e tampouco a questão da composição, como acontece na centralização cubista. Podemos observar concretamente essas características em outro grupo de trabalhos seminais, telas e trabalhos em papel expostos em sua primeira individual na Galeria Betty Parsons, em maio de 1951, logo antes do verão no Black Mountain College e da viagem à Itália.

The Lily White, de 1950, por exemplo, apresenta um diagrama de linhas e números, como o tabuleiro de um jogo que pode ser lido de todos

${ }^{43}$ Cy + Roman Steps $(I-V), 1952$, folha de contato analógica médio formato pb, impressa ca.1997. 
os lados pelos participantes no entorno da mesa. Realizado numa aula de modelo-vivo em que Rauschenberg dava as costas para a modelo, parece um labirinto dos caminhos incertos, pois existem vários arrependimentos que o artista devia ter corrigido na espessa camada de tinta fresca. Uma estrelinha vermelha de um lado e a inscrição do título fogem da padronagem preta sobre o branco, incerto e manchado pelas correções. Em Mother of God, (fig.1) ${ }^{44}$ outro destaque da exposição, uma colagem de vários mapas é vedada por um círculo de tinta branca bem no meio, e por uma faixa em baixo, anulando o acesso às referências topográficas. $\mathrm{O}$ título, que remete a um sujeito clássico da pintura religiosa ocidental, completa o universo simbólico do quadro.

Das treze obras exibidas nessa mostra, relata Calvin Tomkins em uma biografia do artista, somente quatro sobreviveram a um incêndio no depósito onde haviam sido guardadas logo após a mostra, na casa dos sogros de Rauschenberg, então casado com a artista Susan Weil. ${ }^{45}$ Do que se perdeu no fogo, como Should Love Come First? (fig.5) ${ }^{46}$, restam apenas os registros fotográficos de Aaron Siskind. Ou seja, enquanto esse conjunto de obras vira cinzas, a maioria das Scatole e Feticci Personali se dispersará nas águas do rio Arno, em um movimento que aponta para o peso da permuta na obra de Rauschenberg, pois as obras sobrevivem somente como reproduções.

Salta aos olhos a fotogenia de Should Love Come First? característica que pode ser estendida a toda a produção de Rauschenberg, mas principalmente aos trabalhos em papel, por questões de escala e pelo grafismo do preto e branco. A fotografia reproduz fielmente os detalhes orgânicos da tinta, da impressão do pé e de algumas pinceladas espessas que recortam as informações, e valoriza ao mesmo tempo a qualidade gráfica dos diagramas e do texto retirado dos jornais. O achatamento prejudica, por exemplo, a qualidade pictórica de Pollock favorece essa imagem, confirmando a sua planitude radical. ${ }^{47}$

Em Frases de impacto, imagens de impacto, um vídeo de 1986 (fig.5) ${ }^{48}$, Farocki conversa com Vilém Flusser sobre a relação entre

\footnotetext{
${ }^{44}$ Robert Rauschenberg, Mother of God, 1950, Óleo, esmalte, mapas impressos, jornais e tintas metálicas em Masonite, $121.9 \times 81.6 \mathrm{~cm}$.

${ }^{45}$ In Off the Wall: A Portrait of Robert Rauschenberg, 2005.

${ }^{46}$ Robert Rauschenberg, Should Love Come First, 1951, tinta óleo, papel impresso e grafite sobre tela, $61.6 \times 76.2 \mathrm{~cm}$ e Harun Farocki, Frases de impacto, imagens de impacto. Uma conversa com Vilélm Flusser, 1986, video digital, cor, 13'. Frame do filme.

47 Curiosamente, ao conseguir imagens radicalmente superficiais, onde uma multiplicidade de signos são nivelados como em uma página de jornal, Rauschenberg, afirmando e superando o cânone de Greenberg.

${ }^{48}$ Robert Rauschenberg, Should Love Come First, 1951, tinta óleo, papel impresso e grafite sobre tela, $61.6 \times 76.2 \mathrm{~cm}$ e Harun Farocki, Frases de impacto, imagens de
} 
imagens e texto na primeira página do cotidiano sensacionalista alemão Bild Zeitung, literalmente "jornal com imagens". Flusser nota que em teoria a leitura da página se daria como em um todo fenomenológico, onde os nossos olhos "vagariam erraticamente" entre a estrutura linear da escrita, que racionaliza os fatos e estimular o pensamento crítico, e os dados subjetivos das imagens, que "normalmente abordamos observandoas segundo uma maneira muito pessoal", sincronizando o nosso olhar e estimulando um pensamento crítico. ${ }^{49}$ As imagens deviam estar ali para esclarecer o texto, ou o contrário - no entanto, como em Should Love Come First? mas por razões perversas, da ordem da mercantilização do horror, os dois registros se sobrepõem e se misturam até literalmente, como a imagem de um cadáver que invade a manchete.

Existe um acordo especial entre texto e imagem, que é forçar o texto à constituição de uma imagem e transformar imagens em informação conceitual, ou torna-las quase slogans.

Flusser nota que que existe um clima mágico e contraditório de brutalidade, onde imagens (fotográficas) que veiculam valores compartilhados e eternos, como o amor materno do retrato da mãe, são desmentidas pelo teor da informação, que relata uma notícia chocante, destruindo em nossa imaginação a imagem da mãe realizada e, nessa exposição, atacando a sua dignidade: "ela teve que se ajoelhar. Baleada na nuca" ${ }^{50}$. A configuração caótica da página, é funcional à dupla moral, ou ao tom demagógico da linha editorial de Bild Zeitung, que, segundo Farocki, ampara-se em valores compartilhados para não apenas relatar, mas também evocar a sensação de ódio e violência com essa justaposição. O fotográfico nesse caso é funcional ao ruído gerado pela composição, que interrompe o tempo inteiro o processo de construção de opinião. Esse uso extremo da diagramação da página como interface entre nos e o codidiano que bloqueia o senso crítico, cujo funcionamento é preanunciado de forma visionária por Rauschenberg, traz a urgência da dúvida de Farocki na frente de sua ilha de edição, ou seja, trata-se de codificar um segredo ou de mantê-lo? ${ }^{51}$

impacto. Uma conversa com Vilélm Flusser, 1986, video digital, cor, 13'. Frame do filme.

${ }^{49}$ Transcrição da fala do filme.

${ }^{50}$ Idem.

${ }^{51}$ Interface. 
Bibliografia

EHMANN, Antje e ESPADA, Eloisa (Org.), Harun Farocki: quem é responsável? Rio de Janeiro: Publicações IMS, 2019.

BALSOM, Erica, "Architectures of Exhibition", in Exhibing Cinema in Contemporary Art, Amsterdam University Press, 2009.

FOSTER, Hal, "Vision Quest", in ArtForum, Vol.43, N.3, Nov. 2004.

FLUSSER, Vilém, O universo das imagens técnicas. Elógio da superficialidade, São Paulo: Annablume, 2012.

STEINBERG, Leo, Outros Critérios, São Paulo: Cosac e Naify, 2008.

JAMESON, Fredric, A virada cultural: reflexões sobre o pos moderno, Rio de Janeiro: Civilização Brasileira, 2006.

CAGE, John, Silence: Lectures and Writings, Middletown: Wesleyan University Press, 1961.

BRYSON, Norman, "The Gaze in the Expanded Field", in Foster (Org.), Vision and Visuality, Seattle: Bay Press, 1988.

LACAN, Jaques, "O que é um quadro" In O Seminário. Livro 11. Os quatro conceitos fundamentais da psicanálise, Rio de Janeiro: Zahar, 1982.

Benjamin, "O colecionador", in Passagens, Belo Horizonte, São Paulo: Ed. UFMG, 2008.

CARUSO, "Robert Rauschenberg alla Galleria L'Obelisco. Scatole e feticci personali" in Caratozzolo, Schiaffini e Zambianchi (Org.), Irene Brin, Gaspero del Corso e la Galleria L'Obelisco, Roma: Drago, 2018. Calvin Tomkins Off the Wall: A Portrait of Robert Rauschenberg, London: Picador, 2005. 